\title{
Initial Experience with the SCHWIND ATOS and SmartSight Lenticule Extraction
}

\author{
Kishore Raj Pradhan ${ }^{1 *}$ and Samuel Arba Mosquera ${ }^{2}$ \\ ${ }^{1}$ Matrika Eye Center, Kathmandu, Nepal \\ ${ }^{2} \mathrm{SCHWIND}$ Eye-Tech-Solutions, Kleinostheim, Germany \\ ${ }^{\star}$ Corresponding author: Kishore Raj Pradhan, MD, Matrika Eye Center, Kathmandu, Nepal
}

Received: September 17, 2020; Accepted: September 21, 2020; Published: October 12, 2020

Ten years ago, small incision lenticule extraction (SMILE) was launched on the VisuMAX [1]. Since then, over 2 million SMILE procedures have been performed, and more than 100 peer-reviewed articles have been published (and counting).

SCHWIND eye-tech-solutions has been working on a femtosecond laser to extend its portfolio, with the aim of providing a valid and versatile system for performing corneal cuts for very different indications [2-6].

Among those, lenticule extraction was targeted from the beginning, and SmartSight has been recently introduced as alternative to an already great procedure (offered mainly by CZM VisuMAX $[7,8]$ and more recently under the name CLEAR by Ziemer Z8) [9].

In these years, lenticule extraction has established itself as a mainstream option in laser vision correction, directly competing with alternatives, the like of LASIK and PRK. What has SmartSight (the new kid on the block) to offer as treatment of choice for refractive indications?

These are the current Clinical Guidelines specific for SmartSight with the SCHWIND ATOS as developed in the experience of the authors.

In our routine (preoperative and postoperative) examinations we include (among others):

- Uncorrected Distance Visual Acuity (UDVA)

- Manifest refraction (MRx)

- Corrected Distance Visual Acuity (CDVA)

- Corneal topography (MS-39)

- Slit lamp examination

- Optical Coherence Tomography (MS-39).

\section{Initial Experiences}

Small incision lenticule extraction is a commonly used technique for correction of refractive error. It involves making a small incision in the peripheral cornea and cutting a lenticule in the stroma. Both the incision and lenticule are cut with a femtosecond laser. Since its introduction, Small Incision Lenticule Extraction has received both $\mathrm{CE}$ and FDA approval. There are many studies, which demonstrate the clinical safety and efficacy of Small Incision Lenticule Extraction. Further, Small Incision Lenticule Extraction may be associated with less dryness, pain and faster wound healing compared to LASIK (laser assisted in situ keratomileusis) and PRK (photorefractive keratectomy).

Dr. Pradhan is an experienced corneal and refractive surgeon. He has performed over 10000 Small Incision Lenticule Extraction procedures. Once the ATOS device was available, he decided to adopt the new device able to perform SmartSight procedures.

The main technical aspects of the ATOS include:

Semi-automated centering of patient eye, including static cyclotorsion compensation imported from SCHWIND SIRIUS.

An eye-tracker for the docking procedure includes pupil recognition, enabling an objective treatment offset (from the diagnostic device), as well as cyclotorsion correction during and after docking procedure.

Other remarkable technical aspects are a high Repetition Rate (in the $\mathrm{MHz}$ range, providing a High Speed system), high Numerical Aperture (enabling excellent resolution), or low Pulse Energy (i.e. low dose). Finally, the optical system provides the same cutting across the whole cornea (both laterally as well as in depth).

The lenticule itself does not use any side cut, thus it does not add any minimum lenticule thickness. Further to that, the lenticule tapers towards the periphery following a refractive progressive true TZ (considering the curvature gradient), in an attempt to reduce epithelial remodeling, and inducing less regression.

Lenticules are differently shaped compared to VisuMax, thus require a modification of the techniques and a learning curve, in order to find both cutting layers quickly. The lenticule edge design of the ATOS is to make a progressive refractive transition as smooth as possible. That is elegant, but different from what other systems provide. 
An important aspect is that the upper cut (cap/flap) is not parallel to $\mathrm{PI} /$ corneal surface but steeper (slightly bent inwards, providing some 80-100 $\mu \mathrm{m}$ extra tolerance for potential decentrations of the cap/flap) and that all surface cuts run outbounds (lower cut, cap, and flap).

As usual, the initial aims were gaining confidence with the system and developing nomograms for the subsequent experiences (this is a continuous process).

We followed typical inclusion criteria for laser vision correction, including (among others): Subjects 18 years of age or older, able to comprehend and sign an ICF, stable refraction, discontinuation of the CLs.

When we started using the system for refractive corrections, we were applying only spherical lenticules (without cylindrical component). Even if the patients showed a low-to-moderate astigmatism (typically below $0.75 \mathrm{D}$ cylindrical error), the plan was based on the SEQ as spherical treatment. Further to that, to facilitate the lenticule extraction, we started with lenticule thicknesses above $100 \mu \mathrm{m}$ (i.e. with spherical powers above $-7 \mathrm{D}$ of myopia). The first treated case is depicted in Figure 1.

Since the initial experiences were quickly encouraging, rather soon it was decided to incorporate astigmatism to the treatment spectrum (typically below $3 \mathrm{D}$ cylindrical error), and reduce the lenticule thickness to $85 \mu \mathrm{m}$ or more (maximum myopic meridian of $-6 \mathrm{D}$ or more). With those indications, the laser settings and the technique have been refined. An example case for a moderate compound myopic astigmatism refractive correction is shown in Figure 2.

For the last $100+$ treatments, we have been using the same laser settings and refined technique, and continuously decreased the attempted lenticule thickness. An example case for a low-to-moderate refractive correction is shown in Figure 3.

The outcomes in terms of UDVA can be seen in Figure 4. The first 16 treatments were performed without astigmatism correction, the next 52 treatments served for finding optimum laser settings and refinements in the technique, whereas the last $100+$ treatments have been performed with the same settings and technique.

As for the settings we are using now, they include:

Spot/Track distance: $4.0 \mu \mathrm{m}$

Pulse Energy: 120 nJ

Treatment time: $33 \mathrm{~s}$ for SmartSight, $26 \mathrm{~s}$ for flaps

Total energy: $650 \mathrm{~mJ}$ for SmartSight, $350 \mathrm{~mJ}$ for flaps

Avg. Dose: $0.65 \mathrm{~J} / \mathrm{cm}^{2}$

Avg. Laser Power: $68 \mathrm{~mW}$.

In this short term, we have successfully completed 185 SmartSight, 174 flaps with the ATOS device, along with further 267 SmartSurf procedures with the SCHWIND AMARIS.

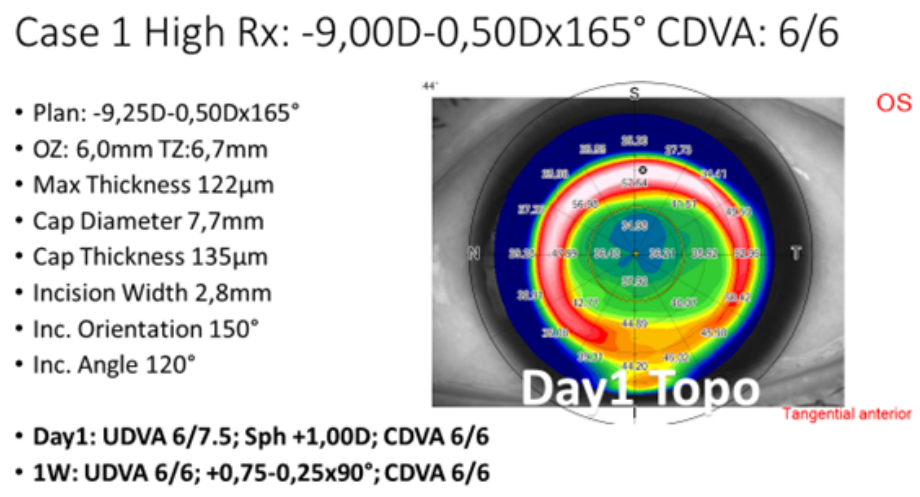

Figure 1: Example treatment of a high myopic treatment, including settings and POD1 topography.



Figure 2: Example treatment of a moderate compound myopic astigmatism treatment, including settings and POD1 topography. 
Case 3 Low Rx: $-3,75 D-0,50 D \times 175^{\circ}$ CDVA: 6/6

- Plan: -3,75D-0,50Dx175

- OZ: 6,0mm TZ:6,7mm

- Max Thickness $69 \mu \mathrm{m}$

- Cap Diameter 7,7mm

- Cap Thickness $130 \mu \mathrm{m}$

- Incision Width 2,8mm

- Inc. Orientation $150^{\circ}$

- Inc. Angle $120^{\circ}$

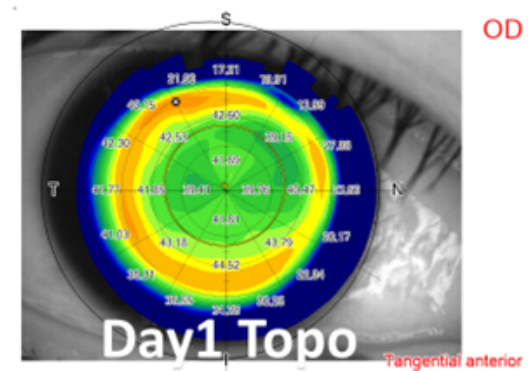

- Day1: UDVA 6/6; Sph +0,75D; CDVA 6/6

- 1W: UDVA 6/6; Sph +0,50D; CDVA 6/6

Figure 3: Example treatment of a low-to-moderate myopic treatment, including settings and POD1 topography.

\section{Clinical Guidelines}

In the gained experience, we have found that oversizing the cap by $\sim 0.7 \mathrm{~mm}$ wider than the $\mathrm{TZ}$ provides sufficient room for surgical manouvers and reduces the cap diameter ( $7.8 \mathrm{~mm}$ to $8.5 \mathrm{~mm})$.

\section{High Corrections}

In order to preserve RST we recommend moderate OZs (6.0-6.5 $\mathrm{mm}$ seem $\mathrm{OK}$ in our experience for corrections above $-7 \mathrm{D})$ combined with thin caps $(<120 \mu \mathrm{m})$. So that for high corrections a safer RST level can be respected after the extraction.

\section{Thin Corneas}

For the same reason, thin caps $(<120 \mu \mathrm{m})$ are preferred for thin corneas.

\section{Low Myopic Corrections}

For low corrections (below $-4 \mathrm{D}$ ) large OZ diameters $(>7.0 \mathrm{~mm}$ diameter) can be used to provide better quality of vision.

\section{Cyclotorsion}

Since the cyclotorsion is acquired upon docking, the epithelium is intact, cyclotorsional/eye registration is actually improved as there is no corneal manipulation prior to treatment.

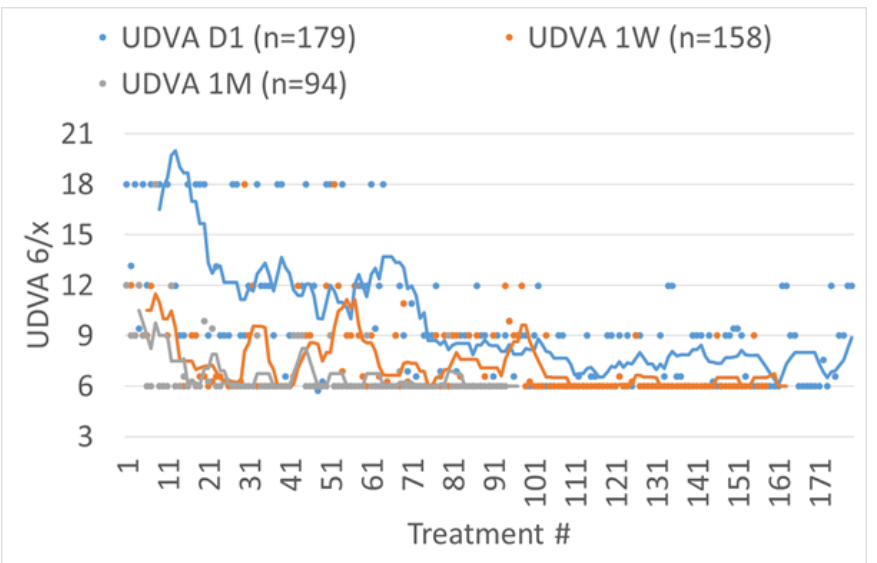

Figure 4: UDVA for consecutive treatments reported for POD1, 1-week, and 1-month follow-up. The first 16 treatments were performed without astigmatism correction, the next 52 treatments served for finding optimum laser settings and refinements in the technique, whereas the last $100+$ treatments have been performed with the same settings and technique.
We present here the outcomes of the SmartSight procedures at POD1, $1 \mathrm{~W}$, and $1 \mathrm{M}$ follow-ups.

\section{UDVA}

For the overall cohort, UDVA at Dayl was $6 / 6$ in $37 \%$ of the cases, improving to $71 \%$ and $83 \%$ at $1 \mathrm{~W}$ and $1 \mathrm{M}$, respectively. At $1 \mathrm{M} 96 \%$ and $99 \%$ achieved $6 / 9$ and 6/12 UDVA, respectively. This can be seen in Figure 5.

\section{UDVA Postop vs. CDVA Preop}

For the overall cohort, UDVA at Day 1 was within 1 line of preop CDVA in $72 \%$ of the cases, improving to $84 \%$ and $97 \%$ at $1 \mathrm{~W}$ and 1 $M$, respectively (Figures 6 and 7).

\section{Scattergram}

For the overall cohort, achieved SEQ at Day 1 was overcorrected by $13 \%$, improving to $7 \%$ and $5 \%$ at $1 \mathrm{~W}$ and $1 \mathrm{M}$, respectively. Whereas astigmatism was under corrected by $3 \%$ at Day 1 and $1 \mathrm{~W}$, and by $6 \%$ at $1 \mathrm{M}$, respectively (Figure 8).

\section{Some Details about the Workflow}

No events of suction loss (despite using a single size large diameter PI) were recorded. The dissection was always easy (even in the

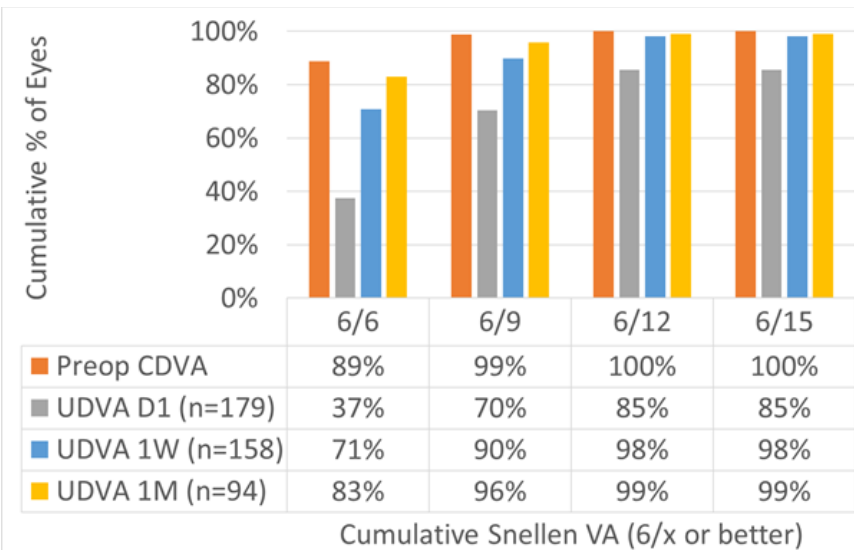

Figure 5: For the overall cohort, UDVA at Day 1 was $6 / 6$ in $37 \%$ of the cases, improving to $71 \%$ and $83 \%$ at $1 \mathrm{~W}$ and $1 \mathrm{M}$, respectively. At $1 \mathrm{M}, 96 \%$ and $99 \%$ achieved $6 / 9$ and $6 / 12$ UDVA, respectively. 


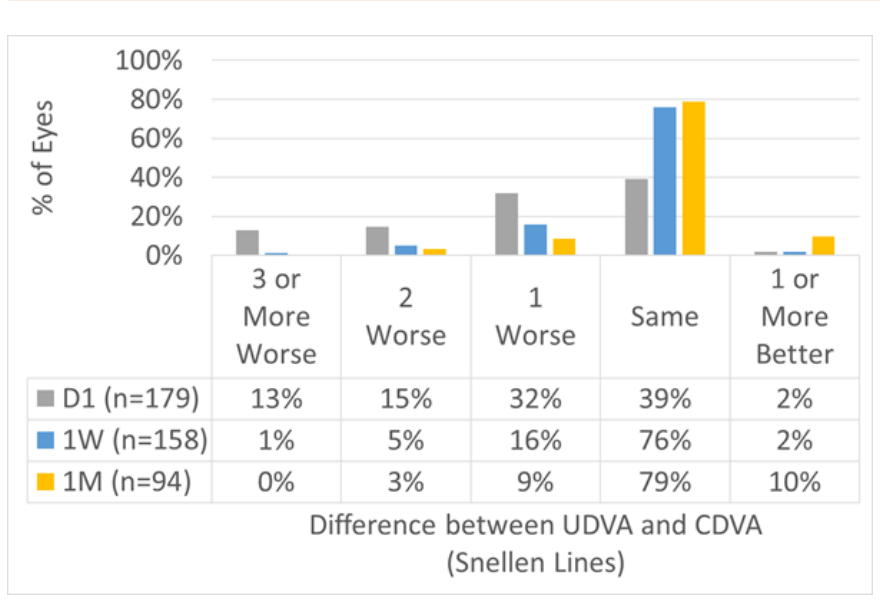

Figure 6: For the overall cohort, UDVA at Day 1 was within 1 line of preop CDVA in 72\% of the cases, improving to $84 \%$ and $97 \%$ at $1 \mathrm{~W}$ and $1 \mathrm{M}$, respectively.

CDVA

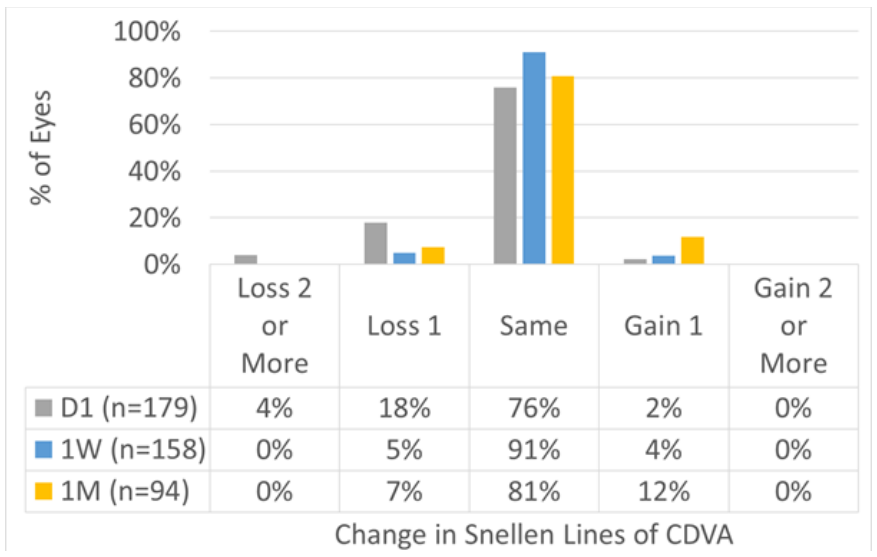

Figure 7: For the overall cohort, CDVA at Day 1 was the same or better than preop in 78\% of the cases, improving to $95 \%$ and $93 \%$ at $1 \mathrm{~W}$ and $1 \mathrm{M}$, respectively.

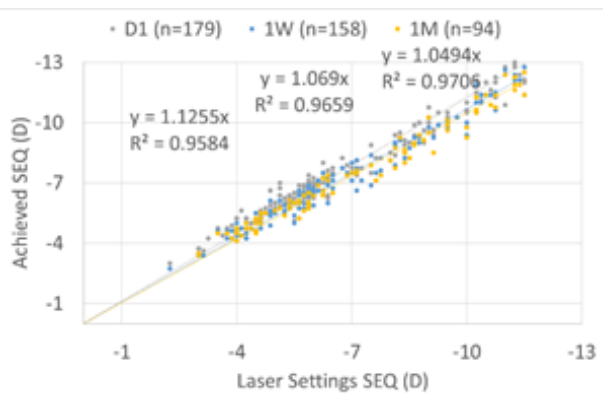

presence of OBLs), and the appearance of the cut really smooth. The optical zones seem larger than planned.

Surgeries went smoother and faster day by day. The final technique uses the incision half way for the upper layer, and half way for the lower layer. Followed by a dissection technique, and wiping the lenticule out through the incision.

\section{Docking and Centration Procedure: Positive Impact and Effect on the Technique}

The Eye-Tracker guided centration and docking shall provide a robust, accurate, and precise alignment of the eye to the system and of the lenticule to the eye. This is reflected in the postop topographies, showing an excellent centration of the correction from Day 1 postop [10].

\section{Do We Need Transition Zones for SmartSight?}

30 years ago TZs were deemed not necessary for ablation procedures, and yet TZs represented a huge improvement in the outcomes. TZs may be important for SmartSight since TZs improve the corneal curvature gradient postop (thus also the HOAs), improving the short term stability. TZs together with no minimum lenticule thickness may lead to less epithelial remodeling and less undercorrection/regression.

\section{Overall Summary}

Day 1 outcomes are a good metric for refraction. From $1 \mathrm{~W}$ Rx remained stable. UDVA was good at Day 1 with $70 \%$ in $6 / 9$, decimal 0.6 ; improving to $>70 \%$ in $6 / 6$, decimal 1.0 at $1 \mathrm{~W}$ (only $89 \%$ preop). UDVA respect to preop CDVA was good $>90 \%$ within 1 line of preop CDVA from $1 \mathrm{~W}$. CDVA change is also fine, no loss of 2 lines from 1

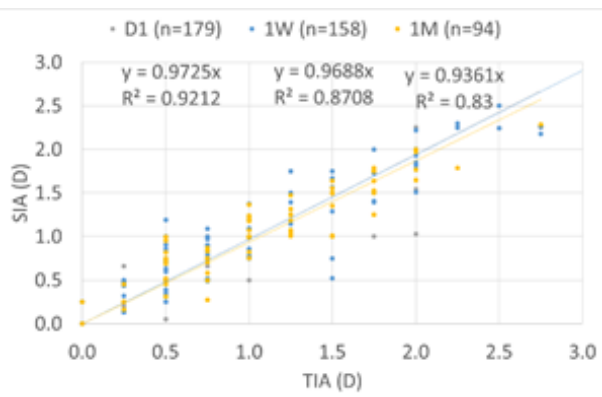

Figure 8: For the overall cohort, achieved SEQ at Day 1 was overcorrected by $13 \%$, improving to $7 \%$ and $5 \%$ at $1 \mathrm{~W}$ and $1 \mathrm{M}$, respectively. Whereas astigmatism was undercorrected by $3 \%$ at Day 1 and $1 \mathrm{~W}$, and by $6 \%$ at $1 \mathrm{M}$, respectively.

\section{Accuracy of MRx}

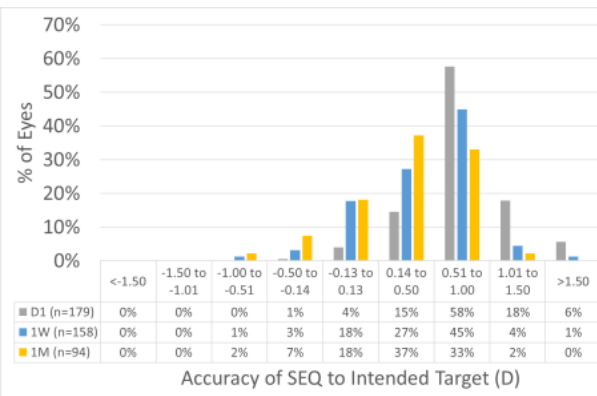

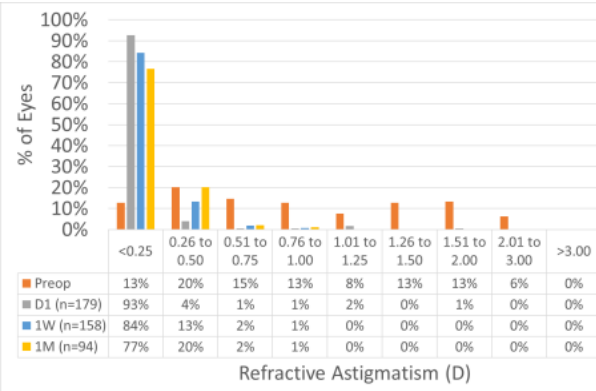

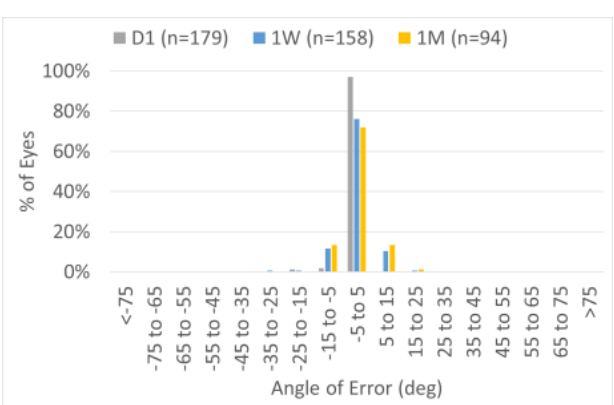

Figure 9: For the overall cohort, SEQ at Day 1 was within $0.50 \mathrm{D}$ in $19 \%$ of the cases, improving to $48 \%$ and $63 \%$ at $1 \mathrm{~W}$ and $1 \mathrm{M}$, respectively. At $1 \mathrm{M}$, $98 \%$ of the treatments were within $1 \mathrm{D}$. Whereas astigmatism was within $0.50 \mathrm{D}$ in $97 \%$ of the cases at Day $1,1 \mathrm{~W}$ and $1 \mathrm{M}$. At $1 \mathrm{~W}$ and $1 \mathrm{M}$, all the treatments were within $1 \mathrm{D}$. As for the angle of error, it was within 15 deg in $99 \%$ of the cases at Day $1,1 \mathrm{~W}$ and $1 \mathrm{M}$. 
W. System slightly overcorrects. The overcorrection reaches $\sim 5 \%$ or $\sim 0.4$ D. Cylinder is properly corrected. Already at Day $1>90 \%$ have a cylinder of $0.5 \mathrm{D}$ or less, this remains at $1 \mathrm{~W}$ and $1 \mathrm{M}$ (Figure 9).

\section{System Slightly Overcorrects?}

Overcorrection shall not be overstressed. Epithelial remodel may continue until $3 \mathrm{M}$ or so. This may induce some epithelial regression. The used personal clinical aim targets a low postoperative plus refraction. The patient population was mainly young, and can easily accommodate $+0.75 \mathrm{D}$. Overall patients are happier with a bit of plus $\mathrm{Rx}$ than with insufficient correction.

\section{Final Thoughts and Conclusion}

Surprisingly ATOS can overcorrect, while cylinder is only slightly undercorrected. Rx and topos essentially do not change from Day 1 to $1 \mathrm{M}$ postop. Wide Ozs and excellent centration was obtained [11].

I still lack experience in high cylinder (above $3 \mathrm{D}$ ) or very thin lenticules (below $45 \mu \mathrm{m}$ ). The minimum lenticule extracted so far was -1.25 D-2.00 Dx60. I have performed 359 treatments (including 174 flaps and 185 SmartSight) without major problems.

ATOS/SmartSight is here to stay and holds a lot of promise. ATOS/ SmartSight has capabilities to unfold full potential and will be a strong contender in the corneal work.

I am excited to get involved in the further ATOS development and I will be part of it!

\section{Epilogue}

The SmartSight treatment offers the right candidate great features. We do anticipate a long-life and a brilliant future for SmartSight. We are aware that SCHWIND eye-tech-solutions continues to push this technique forward with further refinements, evolutions, and innovations, which would continue to strengthen its position.

\section{References}

1. Sekundo W, Kunert KS, Blum M. Br (2011) Small incision corneal refractive surgery using the small incision lenticule extraction (SMILE) procedure for the correction of myopia and myopic astigmatism: results of a 6 month prospective study. JOphthalmol 95(3): 335-339. [crossref]

2. Pradhan KR, Reinstein DZ, Carp GI, Archer TJ, Gobbe M, et al. (2013) Femtosecond laser-assisted keyhole endokeratophakia: correction of hyperopia by implantation of an allogeneic lenticule obtained by SMILE from a myopic donor. J Refract Surg 29(11): 777-778. [crossref]

3. Studer HP, Pradhan KR, Reinstein DZ, Businaro E, Archer TJ, et al. (2015) Biomechanical Modeling of Femtosecond Laser Keyhole endokeratophakia Surgery. J Refract Surg 31(7): 480-486. [crossref]

4. Pradhan KR, Reinstein DZ, Vida RS, Archer TJ, Dhungel S, et al. (2019) Femtosecond Laser-Assisted Small Incision Sutureless Intrastromal Lamellar Keratoplasty (SILK) for Corneal Transplantation in Keratoconus. J Refract Surg 35(10): 663-671. [crossref]

5. Reinstein DZ, Pradhan KR, Carp GI, Archer TJ, Day AC, et al. (2019) Small Incision Lenticule Extraction for Hyperopia: 3-Month Refractive and Visual Outcomes. J Refract Surg 35(1): 24-30. [crossref]

6. Pradhan KR, Reinstein DZ, Carp GI, Archer TJ, Dhungana P (2019) Small Incision Lenticule Extraction (SMILE) for Hyperopia: 12-Month Refractive and Visual Outcomes. J Refract Surg 35(7): 442-450. [crossref]

7. Pradhan KR, Reinstein DZ, Carp GI, Archer TJ, Gobbe M, et al. (2016) Quality control outcomes analysis of small-incision lenticule extraction for myopia by a novice surgeon at the first refractive surgery unit in Nepal during the first 2 years of operation. J Cataract Refract Surg 42(2): 267-277. [crossref]

8. Reinstein DZ, Carp GI, Pradhan KR, Engelfried C, Archer TJ, et al. (2018) Role of laser refractive surgery in cross-subsidization of nonprofit humanitarian eyecare and the burden of uncorrected refractive error in Nepal: Pilot project. J Cataract Refract Surg 44(8): 1012-1017. [crossref]

9. Izquierdo L Jr, Sossa D, Ben-Shaul O, Henriquez MA (2020) Corneal lenticule extraction assisted by a low-energy femtosecond laser. J Cataract Refract Surg 46(9): 1217-1221. [crossref]

10. Reinstein DZ, Pradhan KR, Carp GI, Archer TJ, Gobbe M, et al. (2017) Small Incision Lenticule Extraction (SMILE) for Hyperopia: Optical Zone Centration. J Refract Surg 33(3): 150-156. [crossref]

11. Reinstein DZ, Pradhan KR, Carp GI, Archer TJ, Gobbe M, et al. (2017) Small Incision Lenticule Extraction (SMILE) for Hyperopia: Optical Zone Diameter and Spherical Aberration Induction. J Refract Surg 33(6): 370-376. [crossref]

\section{Citation:}

Kishore Raj Pradhan, Samuel Arba Mosquera (2020) Initial Experience with the SCHWIND ATOS and SmartSight Lenticule Extraction. J Clin Res Med Volume 3(4): $1-5$. 